Research Article

\title{
Simultaneous Determination of 13 Constituents of Radix Polygoni Multiflori in Rat Plasma and Its Application in a Pharmacokinetic Study
}

\author{
Wenhao Cheng, ${ }^{1}$ Yinghui Li, ${ }^{1}$ Wei Yang, ${ }^{2}$ Siyang Wu, ${ }^{2}$ Mengmeng Wei, ${ }^{2}$ Yang Gao, \\ Chen Kang, ${ }^{2}$ Shuofeng Zhang $\mathbb{D}^{1},{ }^{1}$ and Yingfei Li $\mathbb{D}^{2}$ \\ ${ }^{1}$ School of Chinese Pharmacy, Beijing University of Chinese Medicine, Beijing 100102, China \\ ${ }^{2}$ Center for DMPK Research of Herbal Medicines, Institute of Chinese Materia Medica, China Academy of Chinese, \\ Beijing 100700, China
}

Correspondence should be addressed to Shuofeng Zhang; shuofengzhang@sina.com and Yingfei Li; dmpk20121201@163.com

Received 25 June 2019; Revised 28 November 2019; Accepted 18 December 2019; Published 3 March 2020

Academic Editor: Pavel Nesterenko

Copyright (c) 2020 Wenhao Cheng et al. This is an open access article distributed under the Creative Commons Attribution License, which permits unrestricted use, distribution, and reproduction in any medium, provided the original work is properly cited.

\begin{abstract}
Radix Polygoni Multiflori (RPM) has been widely used to treat various diseases in Asian countries for many centuries. Although, stilbenes and anthraquinones, two major components of RPM, show various bioactive effects, it has been speculated that the idiosyncratic hepatotoxicity induced by RPM may be related to these constituents. However, information on the pharmacokinetics of stilbenes and anthraquinones at a subtoxic dose of RPM is limited. A simple and sensitive UPLC-MS/MS bioanalytical method for the simultaneous determination of 13 ingredients of RPM, including chrysophanol, emodin, aloe-emodin, rhein, physcion, questin, citreorosein, questinol, 2,3,5,4'-tetrahydroxystilbene-2-O- $\beta$-D-glucoside, torachrysone-8-O-glucoside, chrysophanol-8-O- $\beta$-D-glucoside, emodin-8-O- $\beta$-D-glucoside, and physcion-8-O- $\beta$-D-glucoside, in rat plasma was established. Acetonitrile was employed to precipitate the plasma with appropriate sensitivity and acceptable matrix effects. Chromatographic separation was performed using a waters HSS C18 column with a gradient elution using water and acetonitrile both containing $0.025 \%$ formic acid within a run time of $9 \mathrm{~min}$. The constituents were detected in negative ionization mode using multiple reaction monitoring. The method was fully validated in terms of selectivity, linearity, accuracy, precision, recovery, matrix effects, and stability. The lower limit of quantitation of the analytes was $0.1-1 \mathrm{ng} / \mathrm{mL}$. The intrabatch and interbatch accuracies were $87.1-109 \%$, and the precision was within the acceptable limits. The method was applied to a pharmacokinetic study after oral administration of RPM extract to rats at a subtoxic dose of $36 \mathrm{~g} / \mathrm{kg}$.
\end{abstract}

\section{Introduction}

Radix Polygoni Multiflori (RPM, Heshouwu in Chinese), the tuberous roots of Polygonum multiflorum Thunb. (Polygonaceae), is one of the most popular traditional Chinese medicines (TCMs) and has been used to treat hyperlipidemia, coronary heart disease, neurosis, and other diseases commonly associated with aging in China and other Asian countries for many centuries [1-3]. Besides its medical uses, RPM has been made as tonic food and beverages and has become popular as a result of the growing interests of general population in phytonutrients and alternative medicines during the past decades. Although it is officially documented in the Chinese Pharmacopoeia, the safety profile of PMR has attracted wide concern due to recently increased reports of hepatic impairment resulting from the use of RPM and RPMcontaining herbal products. Accordingly, the recommended PMR dose in the Chinese Pharmacopoeia was adjusted from 6 to $12 \mathrm{~g}$ in the 2005 edition to $3-6 \mathrm{~g}$ in the 2010 edition due to safety concerns $[4,5]$. The potential liver toxicity of PMR in rats is significant with increasing dose to $20 \mathrm{~g}$ crude drug $/ \mathrm{kg}$ (60-fold clinical dose) [6]; however, hepatotoxicity associated with RPM is also idiosyncratic [7] and not related to the dose, route, or duration of drug administration [8]. 
Unlike Western medicine, TCMs are complex chemical mixtures. The effect of an herbal therapy is not necessarily the result of a single mechanism induced by a single ingredient but a range of activities of multiple compounds working together to produce a medicinal benefit. Although more than 140 compounds were detected in PMR extracts [9], stilbenes and anthraquinones are two major characteristic constituents of RPM. Stilbenes, mainly 2,3,5,4'-tetrahydroxystilbene-2-O- $\beta$-D-glucoside (TSG), possessed antioxidative, antitumor, anti-inflammatory, endothelial protective, neuroprotective, and liver-protective activities, etc. [10-21]. Anthraquinones were reported to possess many biological activities, including immunomodulating, anticancer, antimutation, antibacterial, anticancer, antioxidant, etc. [22-25], with a different effects between free and glycoside forms [26]. However, the hepatotoxic chemicals attributed to RPM-induced idiosyncratic hepatotoxicity [27] remain in dispute [28]. It has been speculated that the toxicity may be related to stilbenes [29] or anthraquinones $[30,31]$. One of the factors that determine susceptibility to uncommon idiosyncratic reactions is that the unique disposition of the drug metabolism manipulating under genetic polymorphisms can alter exposure to toxic metabolites and exceeding the threshold [32]. For example, TSG was able to accelerate the exposure and metabolism of emodin to increase potential PMR-induced liver injury through upregulation activity of CYP1A2 isozyme [33]. Hence that, evaluating the pharmacokinetic behavior of the active constituents of RPM can offer us valuable information for better understanding their pharmacological and/or toxicological effects.

There were articles that had described the pharmacokinetic properties of constituents of RPM, mainly focused on few constituents in RPM [31,34-36]. In fact, studies of those individual components and/or with single administration of PMR constituents do not reflect the real pharmacokinetic characteristics after administration of RPM. Therefore, it is necessary and meaningful to develop an accurate and selective bioanalytical method for the simultaneous determination of more biological ingredients in plasma to understand the characterization and diversity of the pharmacokinetic properties of RPM. The ultraperformance liquid chromatography combined with triple quadrupole tandem mass spectrometry (UPLC-MS/MS), detection using different multiple reaction monitor (MRM) channels at the same time, is a powerful technique used for simultaneous quantification of multiple components in complex matrix due to its very high sensitivity and selectivity. Several LCMS/MS analytical methods determining multicomponents of RPM and the application of pharmacokinetics-related investigations were reported [31, 33, 37, 38]. However, at most 7 analytes of RPM were simultaneous determined according to the reports [38]. Therefore, the aim of this study was to develop and validate a method for simultaneous measurement of 13 components (chrysophanol, emodin, aloe-emodin, rhein, physcion, questin, citreorosein, questinol, TSG, torachrysone-8-O-glucoside (TG), chrysophanol-8-O- $\beta$-D-glucoside (CG), emodin-8-O- $\beta$-D-glucoside (EG), and physcion-8-O- $\beta$-D-glucoside $(\mathrm{PG}))$ in rat plasma using an UPLC-MS/MS and investigate their pharmacokinetics after rats administration of RPM extract.

\section{Materials and Methods}

2.1. Chemicals and Materials. Standards of chrysophanol, emodin, aloe-emodin, rhein, physcion, questin, TSG, emodin-8-O- $\beta$-D-glucoside (EG), physcion-8-O- $\beta$-D-glucoside (PG), and puerarin (IS) were purchased from the Chengdu Chroma-Biotechnology Co., Ltd. (Chengdu, China). Citreorosein, questinol, torachrysone-8-O-glucoside (TG), and chrysophanol-8-O- $\beta$-D-glucoside (CG) were purchased from the Qingdao Advancechem Technology Co., Ltd. (Qingdao, China). The chemical structures of the 13 constituents of RPM and IS are shown in Figure 1.

RPM was purchased from Beijing Tongrentang Pharmaceutical Co., Ltd, and identified by professor Shuofeng Zhang (Beijing University of Chinese Medicine). The voucher specimen (lot no.: YDZY-HSW-20180521) was deposited at $4^{\circ} \mathrm{C}$ in our laboratory. The RPM $(200 \mathrm{~g})$ was refluxed with $70 \%$ ethanol twice $(1: 10, \mathrm{w} / \mathrm{v}), 3 \mathrm{~h}$ for each time. All the solution obtained were put together and condensed by vacuum drier at $50^{\circ} \mathrm{C}$ to get $50 \mathrm{ml}$ extract, containing $4 \mathrm{~g}$ raw herb per milliliter.

LC-grade acetonitrile and formic acid were purchased from Honeywell (Morristown, USA) and Roe Scientific Inc. (Newark, USA), respectively. Ultra-pure water was prepared using a Millipore Milli-Q purification system (Bedford, USA).

\subsection{LC-MS/MS Instrument and Analytical Conditions.} The analysis was performed on an AB Sciex API 5500 Q Trap mass spectrometer (Toronto, Canada), interfaced with a Waters Acquity UPLC separation module. Empower 3.0 and Analyst 1.62 software were used to control UPLC and mass spectrometer, respectively.

Chromatographic separation was achieved on a waters HSS C18 column $\left(100 \times 2.1 \mathrm{~mm}, 1.8 \mu \mathrm{m}\right.$, kept at $\left.40^{\circ} \mathrm{C}\right)$ using a mobile phase containing $0.025 \%$ formic acid that consisted of solvent A (water) and solvent B (acetonitrile). The mobile phase was delivered at $0.3 \mathrm{~mL} / \mathrm{min}$, and a gradient program was used as follows: $0-1 \mathrm{~min}$, held $5 \%$ to $25 \%$ solvent $\mathrm{B}$; 1-3.5 min, linear gradient from $25 \%$ to $35 \%$ solvent $\mathrm{B}$; 3.5-5 min, linear gradient from $35 \%$ to $40 \%$ solvent B; 5 6 min, linear gradient from $40 \%$ to $60 \%$ solvent B; 6-6.1 min, linear gradient from $60 \%$ to $95 \%$ solvent B; $6.1-8$ min, linear gradient from $95 \%$ to $100 \%$ solvent B; and $8-9$ min, held $5 \%$ solvent B.

The MS detection was set in positive multiple reaction monitoring (MRM) mode for the analytes and IS. The turbo spray temperature was maintained at $500^{\circ} \mathrm{C}$. The nebulizer gas (gas 1), heater gas (gas 2), and curtain gas was set at 45, 50 , and 45 psi, respectively. The interface heater was on. The precursor ion, corresponding product ion and dwell time along with declustering potential (DP), entrance potential (EP), collision energy (CE), and collision exit potential (CXP) for each compound were optimized with standard substance. The dwell time was $50 \mathrm{~ms}$ for all analytes. The EP 
<smiles>[R]c1cc(OCC)c2c(c1)C(=O)c1cc([R3])c([R3])c(OCC)c1C2=O</smiles>

\begin{tabular}{lccccc}
\cline { 2 - 5 } Chrysophanol & $\mathrm{R}$ & $\mathrm{R}$ & $\mathrm{R}$ & $\mathrm{H}$ & $\mathrm{CH}_{3}$ \\
\cline { 2 - 5 } Emodin & $\mathrm{H}$ & $\mathrm{H}$ & $\mathrm{H}$ & $\mathrm{OH}$ & $\mathrm{CH}_{3}$ \\
Aloe-emodin & $\mathrm{H}$ & $\mathrm{H}$ & $\mathrm{H}$ & $\mathrm{CH}_{2} \mathrm{OH}$ & $\mathrm{OH}$ \\
Rhein & $\mathrm{H}$ & $\mathrm{H}$ & $\mathrm{H}$ & $\mathrm{H}$ & $\mathrm{COOH}$ \\
Physcion & $\mathrm{H}$ & $\mathrm{H}$ & $\mathrm{H}$ & $\mathrm{OCH}_{3}$ & $\mathrm{CH}_{3}$ \\
Questin & $\mathrm{CH}$ & $\mathrm{H}$ & $\mathrm{H}$ & $\mathrm{OH}$ & $\mathrm{CH}_{3}$ \\
Citreorosein & $\mathrm{H}$ & $\mathrm{H}$ & $\mathrm{H}$ & $\mathrm{OH}$ & $\mathrm{CH}_{2} \mathrm{OH}$ \\
Questinol & $\mathrm{CH}$ & $\mathrm{H}$ & $\mathrm{H}$ & $\mathrm{OH}$ & $\mathrm{CH}_{2} \mathrm{OH}$ \\
CG & $\mathrm{Glc}$ & $\mathrm{H}$ & $\mathrm{H}$ & $\mathrm{H}$ & $\mathrm{CH}_{3}$ \\
EG & $\mathrm{Glc}$ & $\mathrm{H}$ & $\mathrm{H}$ & $\mathrm{OH}$ & $\mathrm{H}$ \\
PG & $\mathrm{Glc}$ & $\mathrm{H}$ & $\mathrm{H}$ & $\mathrm{OCH}$ & $\mathrm{H}$ \\
\cline { 2 - 5 } & & & & &
\end{tabular}<smiles>COc1cc(O[C@@H]2O[C@H](CO)[C@@H](O)[C@H](O)[C@H]2O)c2c(O)c(C(C)=O)c(C)cc2c1</smiles><smiles>OC[C@H]1O[C@@H](Oc2c(O)cc(O)cc2/C=C/c2ccc(O)cc2)[C@H](O)[C@H](O)[C@@H]1O</smiles><smiles>O=c1c(-c2ccc(O)cc2)coc2c([C@@H]3O[C@H](CO)[C@@H](O)[C@H](O)[C@H]3O)c(O)ccc12</smiles>

FIgURE 1: Chemical structures of the 13 constituents of RPM and the IS.

and CXP were set at $-10 \mathrm{~V}$ and $-16 \mathrm{~V}$, respectively. The other detailed mass spectrometric conditions are shown in Table 1.

\subsection{Working Solutions and Quality Control (QC) Samples.} The stock of standard solution was prepared as chrysophanol, emodin, aloe-emodin, rhein, physcion, questin, citreorosein, questinol, TSG, TG, CG, EG, PG, and IS at a concentration of $1 \mathrm{mg} / \mathrm{mL}$. The calibration samples of analytes were prepared by adding a series of different concentration working solution $(5 \mu \mathrm{L})$ to drug-free rat plasma $(45 \mu \mathrm{L})$. Quality control (QC) samples were prepared independently at the concentrations shown in Table 2 for the method validation. All stock solutions and working solutions were stored at $-70^{\circ} \mathrm{C}$ pending use.

2.4. Sample Preparations. Sample preparations were made using the protein precipitation process. $50 \mu \mathrm{L}$ thawed plasma, $10 \mu \mathrm{L}$ IS working solution (puerarin $10 \mu \mathrm{g} / \mathrm{mL}$ ), and $150 \mu \mathrm{L}$ acetonitrile were added to a $1.5 \mathrm{~mL}$ tube in that order. After vortexed for $5 \mathrm{~min}$ and centrifuged at $12,000 \mathrm{~g}$ for $5 \mathrm{~min}$ at $4^{\circ} \mathrm{C}, 150 \mu \mathrm{L}$ of the supernatant was transferred and a $5 \mu \mathrm{L}$ was injected into the UPLC-MS/MS instrument for analysis.

2.5. Method Validations. The developed LC-MS/MS method was performed through complete method validation based on the industrial guidelines for bioanalytical method validation from the US FDA [39].
TABLE 1: The optimized mass spectrometry parameters of the 13 constituents of RPM and IS.

\begin{tabular}{lcccc}
\hline Compound & Q1 mass (Da) & Q3 mass (Da) & DP (V) & CE (V) \\
\hline Chrysophanol & 253.0 & 225.1 & -98 & -37 \\
Emodin & 269.0 & 241.0 & -60 & -36 \\
Aloe-emodin & 269.1 & 240.1 & -100 & -31 \\
Rhein & 283.0 & 256.1 & -60 & -35 \\
Physcion & 283.3 & 240.1 & -60 & -35 \\
Questin & 283.1 & 240.1 & -80 & -36 \\
Citreorosein & 285.0 & 211.0 & -60 & -43 \\
Questinol & 299.0 & 256.1 & -60 & -35 \\
TSG & 405.0 & 311.0 & -80 & -25 \\
TG & 407.0 & 245.0 & -60 & -23 \\
CG & 415.0 & 253.0 & -60 & -20 \\
EG & 431.1 & 269.0 & -120 & -120 \\
PG & 445.0 & 283.0 & -80 & -17 \\
Puerarin (IS) & 415.0 & 295.0 & -200 & -40 \\
\hline
\end{tabular}

2.5.1. Specificity, Selectivity, LLOQ, and Linearity. The blank rat plasma samples from six sources, blank plasma samples spiked with analytes at the lower limit of quantification (LLOQ), and plasma samples obtained from PK studies were analyzed to ascertain the specificity and selectivity of the method for endogenous plasma matrix components.

The LLOQ for the analytes in rat plasma were defined as the lowest concentration giving a signal-to-noise ratio of at least 10, acceptable accuracies of $80-120 \%$, and sufficient precisions within $20 \%$. These were verified by 5 replicate analyses. 
TABLE 2: Calibration curves, correlation coefficients, linear ranges, and LLOQ of the 13 analytes.

\begin{tabular}{lccc}
\hline Compound & Regression equation & Linearity $(r)$ & Linear range $(\mathrm{ng} / \mathrm{mL})$ \\
\hline Chrysophanol & $Y=0.0828 X+0.00155$ & 0.9995 & $1-729$ \\
Emodin & $Y=0.907 X+0.0512$ & 0.9993 & $0.1-72.9$ \\
Aloe-emodin & $Y=0.0652 X+0.00257$ & 0.9994 & $0.1-72.9$ \\
Rhein & $Y=0.465 X+0.119$ & 0.9965 & $0.5-364.5$ \\
Physcion & $Y=0.0253 X+0.0016$ & 0.9948 & $0.5-364.5$ \\
Questin & $Y=1.14 X+0.00681$ & 0.9967 & $0.1-72.9$ \\
Citreorosein & $Y=0.102 X+0.00161$ & 0.9998 & $0.1-72.9$ \\
Questinol & $Y=0.636 X+0.00179$ & 0.9996 & $0.1-72.9$ \\
TSG & $Y=0.1 X+0.0259$ & 0.9969 & $0.3-218.7$ \\
TG & $Y=0.592 X+0.00443$ & 0.9993 & $0.1-72.9$ \\
CG & $Y=0.138 X+0.00767$ & 0.9995 & $0.1-72.9$ \\
EG & $Y=0.54 X+0.0193$ & 0.99 & $0.1-72.9$ \\
PG & $Y=0.0576 X+0.00158$ & 0.9995 & $0.1-72.9$ \\
\hline
\end{tabular}

Matrix-matched calibration curves were generated by plotting the peak ratios of the analytes to IS vs the nominal concentrations of the calibration standards at $0.1,0.3,0.9$, $2.7,8.1,24.3$, and $72.9 \mathrm{ng} / \mathrm{mL}$ for emodin, aloe-emodin, questin, citreorosein, questinol, TG, CG, EG, PG; 0.3, 0.9, 2.7, 8.1, 24.3, 72.9, and $218.7 \mathrm{ng} / \mathrm{mL}$ for TSG; $0.5,1.5,4.5$, $13.5,40.5,121.5$, and $364.5 \mathrm{ng} / \mathrm{mL}$ for rhein and physcion; and $1,3,9,27,81,243$, and $729 \mathrm{ng} / \mathrm{mL}$ for chrysophanol. Matrix-matched calibration curves were constructed using weighted $\left(1 / X^{2}\right)$ linear regression of the peak area of compounds to internal standard $(Y)$ against the corresponding nominal compound concentration $(X, \mathrm{ng} / \mathrm{mL})$. All the values, except LLOQ, were accepted within $15 \%$ of nominal concentration.

2.5.2. Accuracy and Precision. To assess the intraday and interday precision and accuracy, complete analytical runs were performed on the same day and on three different days, respectively. Intraday precision and accuracy were determined by analyzing six replicates of the LLOQ samples and three different QC samples on the same day. Interday precision and accuracy were also evaluated by analyzing 18 replicates of the LLOQ sample and three different QC samples on three different days (six replicates/day). Precision was expressed as the relative standard deviation (RSD, \%), and the accuracy was expressed as follows: (observed concentration/nominal concentration) $\times 100 \%$.

2.5.3. Recovery and Matrix Effect. The recoveries and matrix effects of the analytes were evaluated to investigate the efficiency of the assay process using three sets samples. Recovery was calculated comparing the peak area of the analytes spiked before extraction (Set 3 ) with the mean peak area of analytes spiked postextraction (Set 2) in three QC concentrations. Matrix effects were determined at the same three QC concentrations and were calculated as the area ratio of the analytes spiked postextraction (Set 2) to the mean same analytes area in neat standard solution (Set 1). The matrix effect were calculated by (area of analytes in Set 2/ Mean area of analytes in of Set 1$) \times 100 \%$ and CV of (area of analytes in Set 2/Mean area of analytes in of Set 1) $\times 100 \%$ as absolute matrix effect and relative matrix effect, respectively. The relative matrix effect should not be greater than $15 \%$. The recovery was calculated as (area of analytes in Set 3/mean area of analytes in Set 2)× $100 \%$.

2.5.4. Stability. The stability of the 13 analytes in rat plasma were assessed by analyzing samples spiked $0.2,2.7$, and $58.3 \mathrm{ng} / \mathrm{mL}$ for emodin, aloe-emodin, questin, citreorosein, questinol, TG, CG, EG, PG; 0.6, 8.1, and $175 \mathrm{ng} / \mathrm{mL}$ for TSG; $1,13.5$, and $291.6 \mathrm{ng} / \mathrm{mL}$ for rhein, physcion; and 2, 27, and $583.2 \mathrm{ng} / \mathrm{mL}$ for chrysophanol, respectively, under four conditions: (1) short-term storage for $4 \mathrm{~h}$ at room temperature; (2) long-term storage for $\left(3\right.$ months at $-70^{\circ} \mathrm{C}$; (3) three freeze-thaw cycles; and (4) posttreatment storage for $24 \mathrm{~h}$ at $6^{\circ} \mathrm{C}$ setting in UPLC autosampler. The concentrations obtained were compared with the nominal values of the spiked samples. The stability was calculated as the percent of the measured concentration to the initial concentration at time zero. The analytes were considered stable if the assay values were within the acceptable limit of accuracy (85.0 115\%).

2.6. Application of the Method to a Pharmacokinetic Study. Male Sprague-Dawley rats (200-240 g) were obtained from Beijing Vital River Laboratory Animal Technology Co., Ltd. (Beijing, China) (SCXK 2016(jing)-0006). The animals were maintained in SPF animal room at temperature $22 \pm 2^{\circ} \mathrm{C}$, $60 \pm 5 \%$ humidity, and $12 / 12 \mathrm{~h}$ day/night cycle. All procedures were approved by the Institutional Animal Ethics Committee and performed in accordance with the Regulations of Experiment Animal Administration issued by the State Committee of Science and Technology of China. RPM extract suspended in an equal volume of 5\% CMC-Na solution and orally administered to the six rats at a single dose of $36 \mathrm{~g} / \mathrm{kg}$ (dose calculated as grams of crude materials used to create the extract per kilogram of rat body weight). The dose was set at a subtoxic level $[40,41]$ to investigate the pharmacokinetic profiles of the constituents of RPM and were approximately 72 times the upper dose $(6 \mathrm{~g} /$ day $)$ of human recommended by the 2015 edition of Chinese Pharmacopoeia [5] (converted to rat dose based on body 
surface area conversion [42]). The calculated doses of compounds based on the contents in the extract were 7.38 , $14.8,13.7,8.82,15.5,11.2,55.8,1.08,1170,11.3,25.7,131.4$, and $13.0 \mathrm{mg} / \mathrm{kg}$ for chrysophanol, emodin, aloe-emodin, rhein, physcion, questin, citreorosein, questinol, TSG, TG, CG, EG, and PG, respectively. Rats were fasted for at least $12 \mathrm{~h}$ before the experiments and had free access to water. Blood samples $(\sim 0.25 \mathrm{~mL})$ were collected from the retinal venous plexus into heparinized $1.5 \mathrm{~mL}$ polythene tubes before administration and 5, 15, and $30 \mathrm{~min}$ and 1, 2, 4, 6, 8, 12 , and $24 \mathrm{~h}$ after dosing RPM extract at dose of $36 \mathrm{~g} / \mathrm{kg}$. The plasma was immediately separated from blood samples and stored frozen at $-70^{\circ} \mathrm{C}$ until analysis.

2.7. PK Parameters and Statistical Analysis. The pharmacokinetic parameters were calculated using the pharmacokinetic software Phoenix ${ }^{\circledR}$ WinNonlin ${ }^{\circledR}$, version 7.0 (Scientific Consulting Inc., Apex, NC, USA). The peak plasma concentration $\left(C_{\max }\right)$ and time to reach $C_{\max }\left(T_{\max }\right)$ were read directly from the experimental data. The total area under the plasma concentration-time curve from time zero to infinity $\left(\mathrm{AUC}_{0-\infty}\right)$ or the last measured time $\left(\mathrm{AUC}_{0-t}\right)$, and terminal half-life $\left(t_{1 / 2}\right)$ were estimated using noncompartmental analysis. All values were expressed as the mean \pm standard deviation $(\mathrm{SD})$.

\section{Results and Discussion}

3.1. LC-MS/MS Optimization Conditions. An UPLC-MS/MS method for the 13 analytes and IS in rat plasma was investigated. Standard solutions at $100 \mathrm{ng} / \mathrm{mL}$ were analyzed to optimize the mass spectrometry conditions. Full scans in positive and negative modes were investigated by monitoring both precursor and product ions in multiple reaction monitoring (MRM) mode to identify the maximum response of the analytes. Results showed using negative scan mode could offer higher sensitivity for the analytes. The optimized MRM parameters are listed in Table 1.

The optimization of the chromatographic condition to separate the analytes was conducted with respect to mobile phase composition, column, and elution based on sensitivity, speed, and peak shape. The use of acetonitrile with a waters HSS C18 column as the optimal mobile, respectively, to achieve good sensitivity and a better peak shape was observed. As a consequence, $0.025 \%$ formic acid solution (gradient elution) was used for high-sample throughput.

\subsection{Method Validation}

3.2.1. Specificity and Selectivity. A sensitive and reliable analytical method was developed and validated under the optimized UPLC-MS/MS conditions to investigate the pharmacokinetics of chrysophanol, emodin, aloe-emodin, rhein, physcion, questin, citreorosein, questinol, TSG, TG, CG, EG, and PG in rats. Blank plasma samples using a protein precipitation procedure have a suitable recovery with the UPLC-MS/MS conditions to ensure less interference of the analytes and internal standard (IS) from plasma. The representative chromatograms for standards of the analytes spiked in blank rat plasma, plasma containing these analytes at LLOQ concentration, and real samples collected at $60 \mathrm{~min}$ after administration of RPM extract are shown in Figure 2. The results show no significant interference from endogenous substances observed under the current analytical conditions, which indicated the specificity and selectivity of the elaborated procedures.

3.2.2. Linearity and the Limits of Detection and Quantification. The linearity of the calibration curves was determined and analyzed with six replicates of concentrations ranging from 0.1 to $364.5 \mathrm{ng} / \mathrm{mL}$ in blank plasma samples. A calibration curve was constructed using $1 / X^{2}$ as weighting factor for each concentration by comparing the peak area ratio with the internal standard. The results demonstrated linearity of $0.1-72.9 \mathrm{ng} / \mathrm{mL}$ for emodin, aloeemodin, questin, citreorosein, questinol, TG, CG, EG, and PG, $1-729 \mathrm{ng} / \mathrm{mL}$ for chrysophanol, $0.5-364.5 \mathrm{ng} / \mathrm{mL}$ for rhein, physcion, and $0.3-218.7 \mathrm{ng} / \mathrm{mL}$ for TSG in rat plasma with correlation coefficients $(r)>0.99$ obtained for the regression lines. The limits of detection (LOD) and quantification (LLOQ) for all 13 bioactive components were $0.1-1 \mathrm{ng} / \mathrm{mL}$, which showed excellent reproducibility and sufficient concentrations for oral administration of the herbal formulation in the subsequent PK study (Table 2).

3.2.3. Precision and Accuracy. The intraday and interday accuracy and precision (\% RSD) data for the 13 components are presented in Table S1. The intraday and interday accuracy values for the 13 analytes ranged $89.0-109 \%$ and $87.1-107 \%$, respectively. The intraday and interday precision values for the 13 analytes ranged $2.09-10.9 \%$ and $1.83-10.3 \%$, respectively.

3.2.4. Recovery and Matrix Effect. The recovery of the 13 analytes from rat plasma was performed after the extraction procedure was assessed in three QC level samples. The mean recovery for all analytes was between $89.9 \%$ and $107 \%$ (Table S2). The absolute matrix effects of chrysophanol, emodin, aloe-emodin, rhein, physcion, questin, citreorosein, questinol, TG, and EG were between $88.0 \%$ and $109 \%$. However, the absolute matrix effects of TSG, CG, and PG ranged from 55.6 to $79.5 \%$. However, the relative matrix effect was $\leq 13.1 \%$ for all analytes, indicating that the existed response suppression of TSG, CG, and PG comprised TSG, CG, and PG analytical sensitivity without sacrificing the accuracy and reliability (Table S2).

3.2.5. Stability. Stock solutions of the 13 analytes and the IS in methanol were stable for at least 4 weeks at $-70^{\circ} \mathrm{C}$. The 13 analytes were all stable in situations mimicking those encountered during sample storage, handling, and analysis, for all the test, rat plasma samples (freeze/thaw stability during and after three cycles from $-70^{\circ} \mathrm{C}$ to room temperature, short-term stability at room temperature for $4 \mathrm{~h}$, 

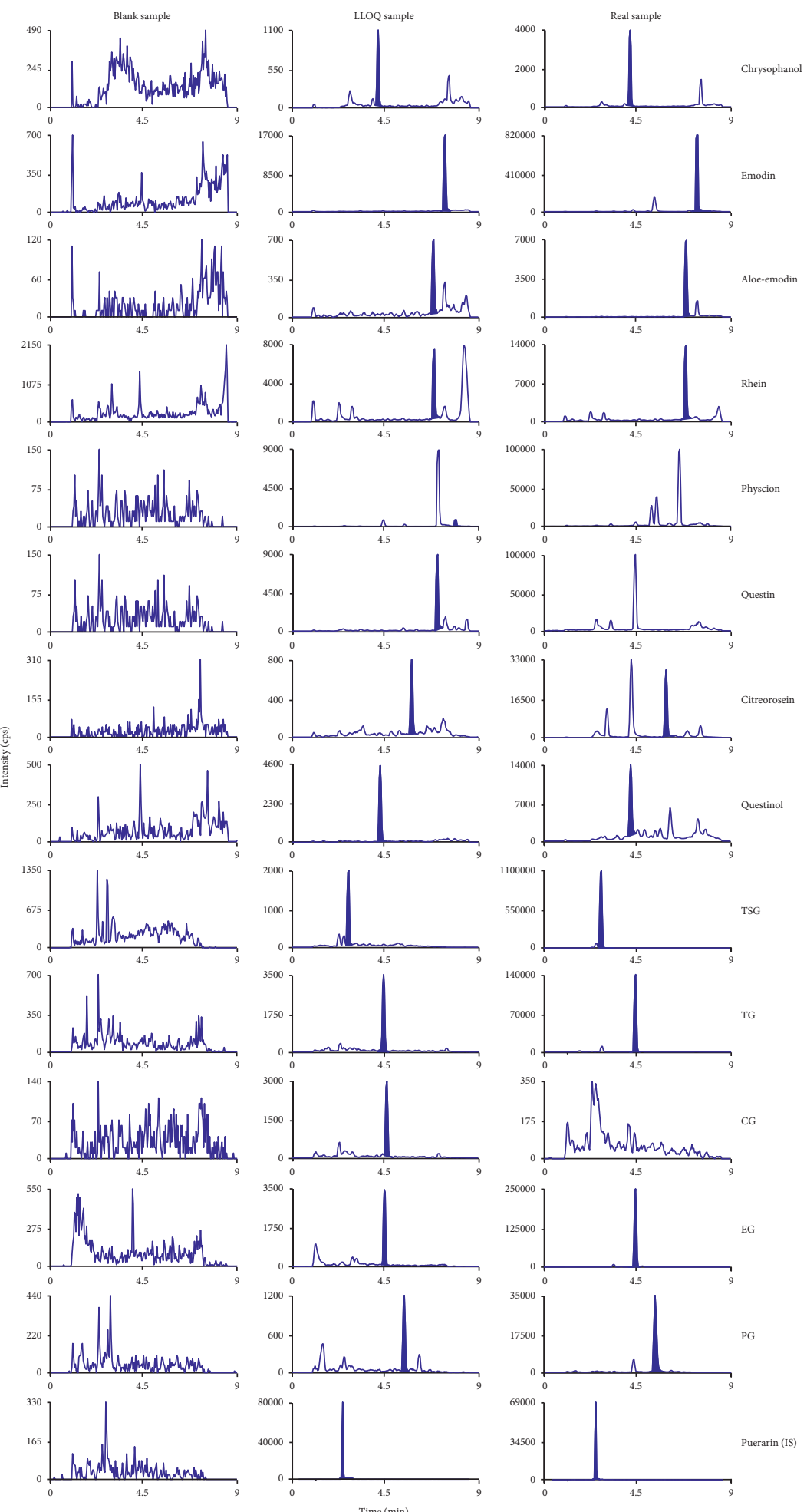

FIgURE 2: Representative MRM chromatograms of the 13 analytes and IS in blank plasma, LLOQ, and real samples. Physcion, questin, and CG were not detected in real samples.

and long-term storage at $-70^{\circ} \mathrm{C}$ for 3 months) and the supernatants resulting from the acetonitrile-precipitated plasma samples (autosampler storage stability at $6^{\circ} \mathrm{C}$ for $24 \mathrm{~h}$ ) were between $87.6 \%$ and $112 \%$ of nominal concentration and well within the limits of acceptability (not exceeding $\pm 15 \%$, Table S3).
3.3. Application to Pharmacokinetic Study. The method was acceptably validated and used to determine 13 constituents of RPM in rat plasma after orally administration of RPM extract at doses of $36 \mathrm{~g}$ crude herb $/ \mathrm{kg}$.

After oral administration of RPM extract, three constituents of RPM, including physcion, questin, and CG, were 


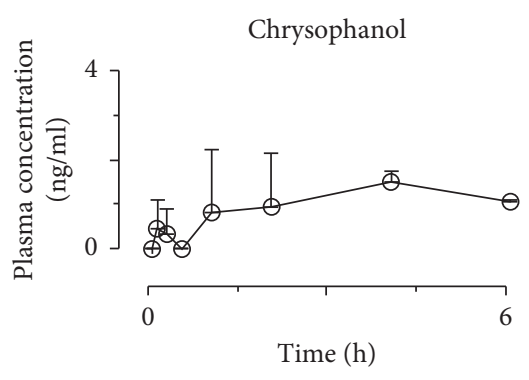

(a)

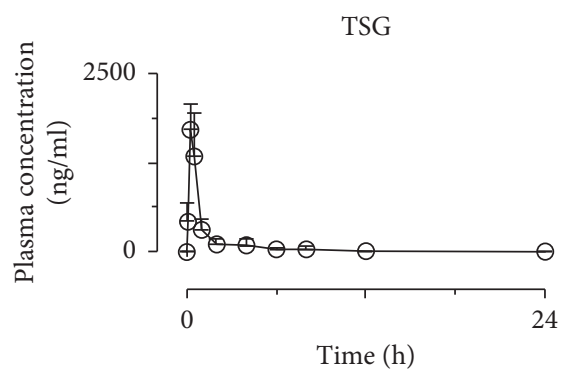

(d)

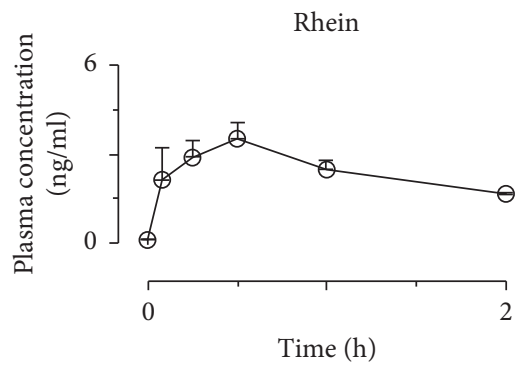

(g)

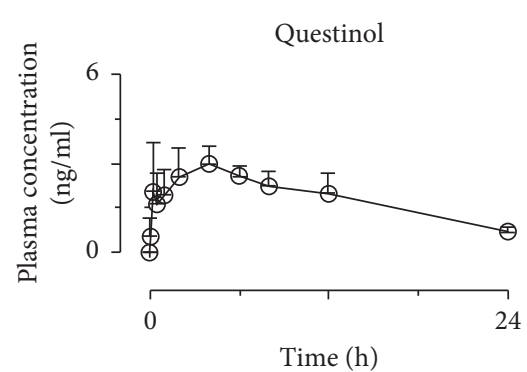

(b)

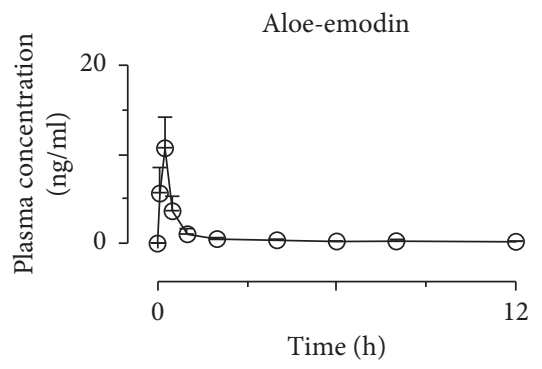

(e)

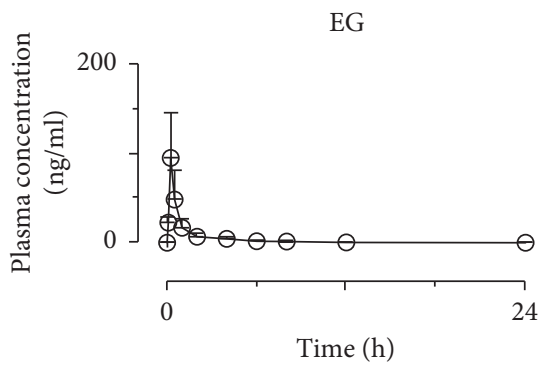

(h)

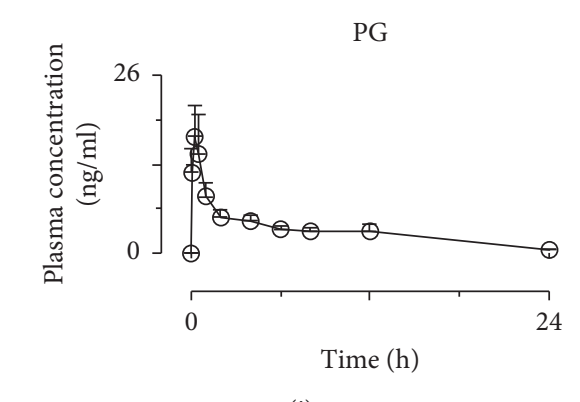

(j)

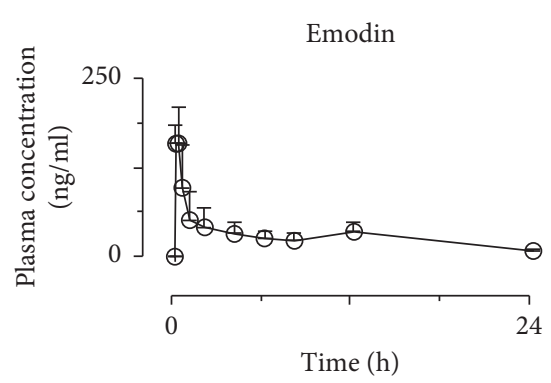

(c)

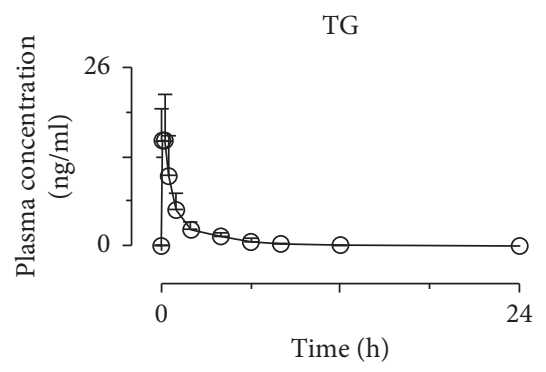

(f)

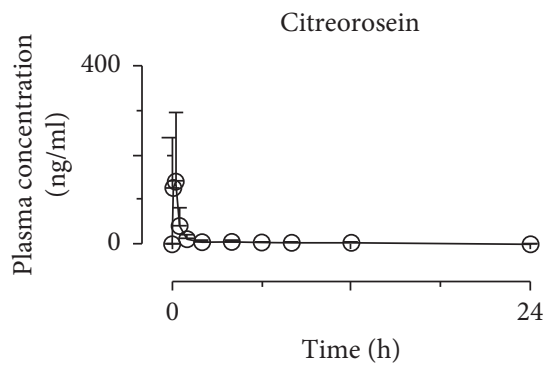

(i)

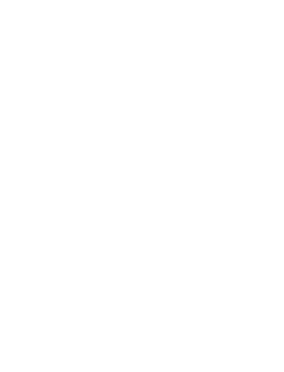

FIgURE 3: Mean plasma concentration-time profiles of the 10 constituents of RPM. The upper error bars represent the standard deviation obtained from six replicates.

too low to be detected and could not get pharmacokinetic parameters. However, chrysophanol, aloe-emodin, and rhein were detected no longer than 6,12 , and $2 \mathrm{~h}$ plasma samples, respectively, after administration of RPM extract to rats.

The mean plasma concentration-time profiles of the detected 10 components after a single dose of RPM extract in rats are shown in Figure 3; the plasma pharmacokinetic parameters of the constituents was different as summarized in Table 3. The $T_{\max }$ values of emodin, aloe-emodin, rhein, citreorosein, TSG, TG, EG, and PG were 0.19 \pm 0.09 , $0.22 \pm 0.07,0.46 \pm 0.10,0.19 \pm 0.09,0.33 \pm 0.13,0.11 \pm 0.07$,
$0.29 \pm 0.10$, and $0.26 \pm 0.13 \mathrm{~h}$, respectively, after single dose oral administration of RPM extract, which indicated the absorbance velocity of these compounds was relatively rapid. However, chrysophanol and questinol reached the $T_{\max }$ at $2.22 \pm 1.76$ and $4.38 \pm 4.03 \mathrm{~h}$, respectively, indicating a slow absorbance.

TSG reached the highest $C_{\max }(1743 \pm 401 \mathrm{ng} / \mathrm{mL})$ among the 10 constituents due to its high content in RPM extract $(65.0 \mathrm{mg} / \mathrm{mL})$. The $C_{\max }$ values of three constituents were higher than $100 \mathrm{ng} / \mathrm{mL}$, including emodin (175 \pm $33.8 \mathrm{ng} / \mathrm{mL})$, citreorosein $(149 \pm 147 \mathrm{ng} / \mathrm{mL})$, and EG $(101 \pm 47.4 \mathrm{ng} / \mathrm{mL})$ with their contents 14.8, 55.8, and 
TABLE 3: Pharmacokinetic parameters of 10 analytes after oral administration of RPM extract $(n=6)$.

\begin{tabular}{|c|c|c|c|c|c|c|}
\hline Compound & $C_{\max }(\mathrm{ng} / \mathrm{ml})$ & $T_{\max }(\mathrm{h})$ & $t_{1 / 2}(\mathrm{~h})$ & $\mathrm{AUC}_{0-t}(\mathrm{ng} \cdot \mathrm{h} / \mathrm{ml})$ & $\mathrm{AUC}_{0-\infty}(\mathrm{ng} \cdot \mathrm{h} / \mathrm{ml})$ & $\mathrm{MRT}_{0-\infty}(\mathrm{h})$ \\
\hline Chrysophanol & $1.90 \pm 0.56$ & $2.22 \pm 1.76$ & $3.18 \pm 0.62$ & $4.28 \pm 1.64$ & $10.3 \pm 1.87$ & $6.76 \pm 2.06$ \\
\hline Emodin & $175 \pm 33.8$ & $0.19 \pm 0.09$ & $8.37 \pm 4.17$ & $686 \pm 187$ & $801 \pm 233$ & $11.8 \pm 5.27$ \\
\hline Aloe-emodin & $11.3 \pm 3.10$ & $0.22 \pm 0.07$ & $3.44 \pm 1.40$ & $7.28 \pm 3.25$ & $8.46 \pm 3.44$ & $3.17 \pm 1.54$ \\
\hline Rhein & $1.06 \pm 0.24$ & $0.46 \pm 0.10$ & $1.18 \pm 0.39$ & $1.11 \pm 0.63$ & $2.31 \pm 0.51$ & $1.83 \pm 0.56$ \\
\hline Citreorosein & $149 \pm 147$ & $0.19 \pm 0.09$ & $3.97 \pm 1.31$ & $131 \pm 96.9$ & $134 \pm 96.4$ & $5.32 \pm 1.85$ \\
\hline Questinol & $1.20 \pm 0.20$ & $4.38 \pm 4.03$ & $8.90 \pm 2.70$ & $14.2 \pm 2.06$ & $17.3 \pm 2.84$ & $13.6 \pm 4.21$ \\
\hline TSG & $1743 \pm 401$ & $0.33 \pm 0.13$ & $5.98 \pm 2.62$ & $1811 \pm 554$ & $1871 \pm 581$ & $3.66 \pm 0.97$ \\
\hline TG & $18.7 \pm 4.06$ & $0.11 \pm 0.07$ & $2.00 \pm 0.63$ & $21.2 \pm 7.38$ & $21.7 \pm 7.48$ & $2.10 \pm 0.24$ \\
\hline EG & $101 \pm 47.4$ & $0.29 \pm 0.10$ & $3.92 \pm 2.50$ & $82.5 \pm 32.1$ & $83.7 \pm 32.3$ & $2.88 \pm 1.41$ \\
\hline PG & $18.8 \pm 4.85$ & $0.26 \pm 0.13$ & $6.13 \pm 1.06$ & $79.5 \pm 8.95$ & $84.1 \pm 8.31$ & $8.58 \pm 1.72$ \\
\hline
\end{tabular}

$131.4 \mathrm{mg} / \mathrm{mL}$ in RPM extract. The $C_{\max }$ of all other compounds ranged from $1.06 \pm 0.24 \mathrm{ng} / \mathrm{mL}$ to $18.8 \pm 4.85 \mathrm{ng} / \mathrm{mL}$. Moreover, the $\mathrm{AUC}_{0-t}$, another $\mathrm{PK}$ parameter reflecting the levels of systemic exposure, of TSG was $1871 \pm 554 \mathrm{ng} \cdot \mathrm{h} / \mathrm{mL}$. However, the dose of citreorosein $(55.8 \mathrm{mg} / \mathrm{kg})$ in $\mathrm{RPM}$ extract was about 3.8 -fold that of emodin $(14.8 \mathrm{mg} / \mathrm{kg})$ and the $\mathrm{AUC}_{0-t}$ values of citreorosein $(134 \pm 96.4 \mathrm{ng} \cdot \mathrm{h} / \mathrm{mL})$ was 6.0 -fold that of emodin $(801 \pm 187 \mathrm{ng} \cdot \mathrm{h} / \mathrm{mL})$. The relative bioavailability of citreorosein, calculating using the $\mathrm{AUC}_{0-t}$ normalized by molecular weight and dose, was $15.8 \%$ of that of emodin due to the one more hydroxyl in the structure of citreorosein (1,3,8-trihydroxy-6-(hydroxymethyl)anthracene-9,10-dione) comparing with the structure of emodin (1,3,8-trihydroxy-6-methylanthracene-9,10-dione) (Figure 1). The $\mathrm{AUC}_{0-t}$ values of all other compounds ranged from $4.95 \pm 1.90 \mathrm{ng} \cdot \mathrm{h} / \mathrm{mL}$ to $84.1 \pm 8.95 \mathrm{ng} \cdot \mathrm{h} / \mathrm{mL}$. The different content of 10 compounds in RPM extract was one of the reasons leading to different systemic exposure. In addition, as report goes, many natural compounds obtained from herb materials have been identified as substrates, inhibitors, or inducers of various CYPs, and the abovementioned values illustrated that it was possible to have impact on the system exposure of some compounds.

Moreover, the $t_{1 / 2}$ of chrysophanol, emodin, aloe-emodin, rhein, citreorosein, questinol, TSG, TG, EG, and PG was $3.18 \pm 0.62, \quad 8.37 \pm 4.17, \quad 3.44 \pm 1.40, \quad 1.18 \pm 0.39$, $3.97 \pm 1.31,8.90 \pm 2.70,5.98 \pm 2.62,2.00 \pm 0.63,3.92 \pm 2.50$, and $6.13 \pm 1.06 \mathrm{~h}$, respectively. The slow elimination, including compounds of chrysophanol, emodin, aloe-emodin, citreorosein, questinol, TSG, EG, and PG, may be attributed to the complexity of Chinese medicine composition.

\section{Conclusions}

A simple, sensitive, and reliable UPLC-MS/MS method for the determination of the glycosides and aglycones of anthraquinones and 2,3,5,4'-tetrahydroxystilbene-2-O- $\beta$-Dglucoside in rat plasma was developed. This method is faster and more high-throughput with analytical time shortening from $18 \mathrm{~min}$ to $9 \mathrm{~min}$ while the number of simultaneous determined analytes increasing from 7 to 13 comparing with the previous reported method [38]. The method was acceptably validated and applied to a pharmacokinetic study of the constituents after oral administration of RPM extract in rats. The absorption of the glycosides of anthraquinones in an intact form was confirmed in the pharmacokinetic study.

The study of RPM should involve elucidating the PK characteristics of the multiple herbal compounds from RPM and understanding their fates in the body. The results of this study could be relevant to a better understanding of the pharmacokinetics and pharmacodynamics of anthraquinone glycosides and aglycones. These results demonstrated the pharmacokinetics of active ingredients of RPM in vivo and provided useful information for further bridge the gap between the complex chemical composition of the RPM and its pharmacological and/or toxicological effects.

\section{Data Availability}

The data used to support the findings of this study are available from the corresponding author upon request.

\section{Conflicts of Interest}

The authors declare no conflicts of interest.

\section{Acknowledgments}

This study has been financially supported by the National Science and Technology Major Project of China "Key New Drug Creation and Manufacturing Program" (No. 2015ZX09501004-003-005) and the National Natural Science Foundation of China (No. 81773990).

\section{Supplementary Materials}

Table S1: intraday and interday accuracy and precision for the determination of the 13 constituents of RPM in rat plasma. Table S2: recovery and matrix effect of the 13 constituents of RPM in rat plasma. Table S3: stabilities of the 13 constituents of RPM in rat plasma. (Supplementary Materials)

\section{References}

[1] Y. U. Feng and G- A. Bounda, "Review of clinical studies of Polygonum multiflorum Thunb. and its isolated bioactive compounds," Pharmacognosy Research, vol. 7, no. 3, pp. 225-236, 2015.

[2] H. Li, X. Wang, Y. Liu et al., "Hepatoprotection and hepatotoxicity of Heshouwu, a Chinese medicinal herb: context of 
the paradoxical effect," Food and Chemical Toxicology, vol. 108, pp. 407-418, 2017.

[3] L. Lin, B. Ni, H. Lin et al., "Traditional usages, botany, phytochemistry, pharmacology and toxicology of Polygonum multiflorum Thunb.: a review," Journal of Ethnopharmacology, vol. 159, pp. 158-183, 2015.

[4] Chinese Pharmacopoeia Commission, Pharmacopoeia of the People's Republic of China, Vol. 1, China Medical Science and Technology Press, Beijing, China, 2005.

[5] Chinese Pharmacopoeia Commission, Pharmacopoeia of the People's Republic of China, Vol. 1, China Medical Science and Technology Press, Beijing, China, 2010.

[6] X. Gong, M. Liu, L. Gong, Y. Li, and C. Peng, "Study on hepatotoxicity of different dosages of Polygoni multiflori radix praeparata in rats by metabolomics based on UPLC-QTOF-MS," Journal of Pharmaceutical and Biomedical Analysis, vol. 175, Article ID 112760, , 2019.

[7] S. Tujios and R. J. Fontana, "Mechanisms of drug-induced liver injury: from bedside to bench," Nature Reviews Gastroenterology \& Hepatology, vol. 8, no. 4, pp. 202-211, 2011.

[8] C.-Y. Li, C. Tu, D. Gao et al., "Metabolomic study on idiosyncratic liver injury induced by different extracts of Polygonum multiflorum in rats integrated with pattern recognition and enriched pathways analysis," Frontiers in Pharmacology, vol. 7, 2016.

[9] J. Huang, J.-P. Zhang, J.-Q. Bai et al., "Chemical profiles and metabolite study of raw and processed Polygoni Multiflori Radix in rats by UPLC-LTQ-Orbitrap MS n spectrometry," Chinese Journal of Natural Medicines, vol. 16, no. 5, pp. 375-400, 2018.

[10] L. Zhang, Y. C. Rui, Y. Qiu, T. J. Li, H. J. Liu, and W. S. Chen, "Expression of VEGF in endothelial cells and the effects of 2, 3, 5, 4'-tetrahydroxystilbene-2-O-beta-D-glucoside," Acta Pharmaceutica Sinica, vol. 39, no. 6, pp. 406-409, 2004.

[11] G. Ryu, J. H. Ju, Y. J. Park, S. Y. Ryu, B. W. Choi, and B. H. Lee, "The radical scavenging effects of stilbene glucosides from Polygonum multiflorum," Archives of Pharmacal Research, vol. 25, no. 5, pp. 636-639, 2002.

[12] L. Zhang and J. Chen, "Biological effects of tetrahydroxystilbene glucoside: an active component of a rhizome extracted from Polygonum multiflorum," Oxidative Medicine and Cellular Longevity, vol. 2018, Article ID 3641960, pp. 1-15, 2018.

[13] B.-M. Kwon, S.-H. Kim, N.-I. Baek et al., "Farnesyl protein transferase inhibitory components of Polygonum multiflorum," Archives of Pharmacal Research, vol. 32, no. 4, pp. 495-499, 2009.

[14] L.-p. Liu, Z.-p. Liao, D. Yin et al., "The protective effects of Polygonum multiflorum stilbeneglycoside preconditioning in an ischemia/reperfusion model of HUVECs," Acta Pharmacologica Sinica, vol. 31, no. 4, pp. 405-412, 2010.

[15] X. Wang, L. Zhao, T. Han, S. Chen, and J. Wang, "Protective effects of 2,3,5,4'-tetrahydroxystilbene-2-O-beta-d-glucoside, an active component of Polygonum multiflorum Thunb, on experimental colitis in mice," European Journal of Pharmacology, vol. 578, no. 2-3, pp. 339-348, 2008.

[16] J. Xu, Y. Peng, Y. Zeng, Y.-q. Hua, and X.-l. Xu, " $2,3,4^{\prime}, 5-$ tetrahydroxystilbene-2-0- $\beta$-d glycoside attenuates age- and diet-associated non-alcoholic steatohepatitis and atherosclerosis in LDL receptor knockout mice and its possible mechanisms," International Journal of Molecular Sciences, vol. 20, no. 7, p. 1617, 2019.

[17] T. Sun, H. Liu, Y. Cheng et al., "2,3,5,4'-Tetrahydroxystilbene2-O- $\beta$ - $d$-glucoside eliminates ischemia/reperfusion injury- induced $\mathrm{H} 9 \mathrm{c} 2$ cardiomyocytes apoptosis involving in Bcl-2, Bax, caspase-3, and Akt activation," Journal of Cellular Biochemistry, vol. 120, no. 7, pp. 10972-10977, 2019.

[18] J. Shen, Y. Zhang, H. Shen et al., "The synergistic effect of 2,3,5, $4^{\prime}$;-tetrahydroxystilbene-2-O- $\beta$-D-glucoside combined with Adriamycin on MCF-7 breast cancer cells," Drug Design, Development and Therapy, vol. 12, pp. 4083-4094, 2018.

[19] Y.-H. Hwang, S.-J. Kim, H. Kim, and S.-T. Yee, "The protective effects of $2,3,5,4^{\prime}$-tetrahydroxystilbene-2-O- $\beta$-d-Glucoside in the OVA-induced asthma mice model," International Journal of Molecular Sciences, vol. 19, no. 12, p. 4013, 2018.

[20] X. Dong, J. Fu, X. Yin et al., "Emodin: a review of its pharmacology, toxicity and pharmacokinetics," Phytotherapy Research, vol. 30, no. 8, pp. 1207-1218, 2016.

[21] C.-Y. Jiang, X.-Y. Qin, M.-M. Yuan, G.-J. Lu, and Y. Cheng, "2,3,5,4'-tetrahydroxystilbene-2-O-beta-D-glucoside reverses stress-induced depression via inflammatory and oxidative stress pathways," Oxidative Medicine and Cellular Longevity, vol. 2018, Article ID 9501427, pp. 1-13, 2018.

[22] X. Dong, J. Fu, X. Yin, C. Yang, and J. Ni, "Aloe-emodin induces apoptosis in human liver HL-7702 cells through fas death pathway and the mitochondrial pathway by generating reactive oxygen species," Phytotherapy Research, vol. 31, no. 6, pp. 927-936, 2017.

[23] W. Lim, C. Yang, F. W. Bazer, and G. Song, "Chrysophanol induces apoptosis of choriocarcinoma through regulation of ROS and the AKT and ERK1/2 pathways," Journal of Cellular Physiology, vol. 232, no. 2, pp. 331-339, 2017.

[24] J. Yuan, H. Hong, Y. Zhang et al., "Chrysophanol attenuated isoproterenol-induced cardiac hypertrophy by inhibiting Janus kinase 2/signal transducer and activator of transcription 3 signaling pathway," Cell Biology International, vol. 43, no. 6 , pp. 695-705, 2019.

[25] X. Yang, M.-C. Kang, Y. Li, E.-A. Kim, S.-M. Kang, and Y.-J. Jeon, "Anti-inflammatory activity of questinol isolated from marine-derived fungus Eurotium amstelodami in lipopolysaccharide-stimulated RAW 264.7 macrophages," Journal of Microbiology and Biotechnology, vol. 24, no. 10, pp. 1346-1353, 2014.

[26] Z. Uddin, Y. H. Song, M. J. Curtis-Long, J. Y. Kim, H. J. Yuk, and K. H. Park, "Potent bacterial neuraminidase inhibitors, anthraquinone glucosides from Polygonum cuspidatum and their inhibitory mechanism," Journal of Ethnopharmacology, vol. 193, pp. 283-292, 2016.

[27] C. Li, T. Rao, X. Chen et al., "HLA-B*35:01Allele is a potential biomarker for predicting Polygonum multiflorum-induced liver injury in humans," Hepatology, vol. 70, no. 1, 2019.

[28] X. X. Wang JB, X. X. Du, Z. S. Zou, H. B. Song, and X. X. Guo, "Identification and early diagnosis for traditional Chinese medicine induced liver injury based on translational toxicology," China Journal of Chinese Materia Medica, vol. 39, pp. 5-9, 2014.

[29] X. Wu, X. Chen, Q. Huang, D. Fang, G. Li, and G. Zhang, "Toxicity of raw and processed roots of Polygonum multiflorum," Fitoterapia, vol. 83, no. 3, pp. 469-475, 2012.

[30] J. Yu, J. Xie, X.-j. Mao et al., "Hepatoxicity of major constituents and extractions of radix polygoni multiflori and radix polygoni multiflori praeparata," Journal of Ethnopharmacology, vol. 137, no. 3, pp. 1291-1299, 2011.

[31] J. Ma, L. Zheng, Y.-S. He, and H.-J. Li, "Hepatotoxic assessment of Polygoni Multiflori Radix extract and toxicokinetic study of stilbene glucoside and anthraquinones in rats," Journal of Ethnopharmacology, vol. 162, pp. 61-68, 2015. 
[32] N. Kaplowitz, "Idiosyncratic drug hepatotoxicity," Nature Reviews Drug Discovery, vol. 4, no. 6, pp. 489-499, 2005.

[33] Y. Xing, L. Wang, C. Wang et al., "Pharmacokinetic studies unveiled the drug-drug interaction between trans-2,3,5,4'tetrahydroxystilbene-2-O- $\beta$-d-glucopyranoside and emodin that may contribute to the idiosyncratic hepatotoxicity of Polygoni Multiflori Radix," Journal of Pharmaceutical and Biomedical Analysis, vol. 164, pp. 672-680, 2019.

[34] G. Lv, Z. Lou, S. Chen, H. Gu, and L. Shan, "Pharmacokinetics and tissue distribution of 2,3,5, ' ${ }^{\prime}$-tetrahydroxystilbene-2-O$\beta$-d-glucoside from traditional Chinese medicine Polygonum multiflorum following oral administration to rats," Journal of Ethnopharmacology, vol. 137, no. 1, pp. 449-456, 2011.

[35] Y.-Y. Zhao, L. Zhang, Y.-L. Feng et al., "Pharmacokinetics of $2,3,5,4^{\prime}$-tetrahydroxystilbene-2-O- $\beta$-D-glucoside in rat using ultra-performance LC-quadrupole TOF-MS," Journal of Separation Science, vol. 36, no. 5, pp. 863-871, 2013.

[36] G. Lv, H. Gu, S. Chen, Z. Lou, and L. Shan, "Pharmacokinetic profile of $2,3,5,4^{\prime}$-tetrahydroxystilbene-2-O- $\beta$-D-glucoside in mice after oral administration ofPolygonum multiflorumextract," Drug Development and Industrial Pharmacy, vol. 38, no. 2, pp. 248-255, 2012.

[37] L. Zhang, W.-f. Ma, J. Li et al., "Influence of processing on pharmacokinetic of typical constituents in radix polygoni multiflori after oral administration by LC-ESI-MS/MS," Journal of Ethnopharmacology, vol. 148, no. 1, pp. 246-253, 2013.

[38] L. Wang, M. Sang, E. Liu et al., "Rapid profiling and pharmacokinetic studies of major compounds in crude extract from Polygonum multiflorum by UHPLC-Q-TOF-MS and UPLC-MS/MS," Journal of Pharmaceutical and Biomedical Analysis, vol. 140, pp. 45-61, 2017.

[39] Food and Drug Administration, Guidance for Industry: Bioanalytical Method Validation, U.S. Department of Health and Human Services Food and Drug Administration, Rockville, MD, USA, 2018.

[40] T. Wang, J. Y. Wang, Z. X. Zhou et al., "Study on hepatotoxicity of aqueous extracts of Polygonum multiflorum in rats after 28-day oral administration: cholestasis-related mechanism," China Journal of Chinese Materia Medica, vol. 40, no. 11, pp. 2163-2167, 2015.

[41] C. Zhang, R. C. Zhang, and Z. X. Sun, "Study on the hepatoxicity of polygoni multiflori radix and polygoni multiflori rodix praeparata in rats," Journal of Chinese Medicinal Materials, vol. 36, pp. 1416-1419, 2013.

[42] S. Reagan-Shaw, M. Nihal, and N. Ahmad, "Dose translation from animal to human studies revisited," The FASEB Journal, vol. 22, no. 3, pp. 659-661, 2007. 